\title{
Predictors and outcomes of obstructive sleep apnea in patients with chronic obstructive pulmonary disease in China
}

\author{
Pan Zhang ${ }^{1 \dagger}$, Bi Chen ${ }^{2 \dagger}$, Heqing Lou ${ }^{1}$, Yanan Zhu², Peipei Chen ${ }^{1}$, Zongmei Dong ${ }^{1}$, Xuan Zhu ${ }^{1}$, Ting Li ${ }^{1}$ and \\ Peian Lou ${ }^{1 *}$
}

\begin{abstract}
Background: "Overlap syndrome" refers to obstructive sleep apnea (OSA) combined with chronic obstructive pulmonary disease (COPD), and has poorer outcomes than either condition alone. We aimed to evaluate the prevalence and possible predictors of overlap syndrome and its association with clinical outcomes in patients with COPD.

Methods: We assessed the modified Medical Research Council dyspnea scale (mMRC), Epworth sleepiness scale (ESS), COPD assessment test (CAT), Hospital Anxiety and Depression Scale (HADS), Charlson Comorbidity Index (CCI), and STOP-Bang questionnaire (SBQ) and performed spirometry and full overnight polysomnography in all patients. An apnea-hypopnea index $(\mathrm{AHI}) \geq 5$ events per hour was considered to indicate OSA. Risk factors for OSA in COPD patients were identified by univariate and multivariate logistic regression analyses.

Results: A total of 556 patients (66\%) had an AHI $\geq 5$ events per hour. There were no significant differences in age, sex ratio, mMRC score, smoking index, number of acute exacerbations and hospitalizations in the last year, and prevalence of cor pulmonale between the two groups (all $p>0.05$ ). Body mass index (BMI), neck circumference, CAT score, $\mathrm{CCl}, \mathrm{ESS}, \mathrm{HADS}$, and SBQ scores, forced expiratory volume (FEV) ${ }_{1}, \mathrm{FEV}_{1} \%$ pred, $\mathrm{FEV}_{1}$ /forced vital capacity ratio, and prevalence of hypertension, coronary heart disease, and diabetes were all significantly higher and the prevalence of severe COPD was significantly lower in the COPD-OSA group compared with the COPD group $(p<0.05)$. BMI, neck circumference, ESS, CAT, CCI, HADS, hypertension, and diabetes were independent risk factors for OSA in COPD patients $(p<0.05)$. SBQ could be used for OSA screening in patients with COPD. Patients with severe COPD had a lower risk of OSA compared with patients with mild or moderate COPD $(\beta=-0.459$, odds ratio $=0.632,95 \%$ confidence interval $0.401-0.997, p=0.048)$.
\end{abstract}

Conclusion: Patients with overlap syndrome had a poorer quality of life, more daytime sleepiness, and a higher prevalence of hypertension and diabetes than patients with COPD alone. BMI, neck circumference, ESS, CAT, CCI, HADS, hypertension, and diabetes were independent risk factors for OSA in patients with COPD. The risk of OSA was lower in patients with severe, compared with mild or moderate COPD.

Keywords: Chronic obstructive pulmonary disease, Obstructive sleep apnea, Risk factor, Scale, Polysomnography

*Correspondence: Ipa82835415@126.com

†Pan Zhang and Bi Chen have contributed equally to this work.

${ }^{1}$ Department of Control and Prevention of Chronic Non-communicable

Diseases of Xuzhou Center for Disease Control and Prevention, 142 West

Erhuan Road, Xuzhou, Jiangsu, China

Full list of author information is available at the end of the article

\section{Background}

Chronic obstructive pulmonary disease (COPD) is a common, preventable and treatable disease characterized by chronic airflow limitation, which is not fully reversible [1]. Approximately 299.4 million people

(c) The Author(s) 2021. Open Access This article is licensed under a Creative Commons Attribution 4.0 International License, which permits use, sharing, adaptation, distribution and reproduction in any medium or format, as long as you give appropriate credit to the original author(s) and the source, provide a link to the Creative Commons licence, and indicate if changes were made. The images or other third party material in this article are included in the article's Creative Commons licence, unless indicated otherwise in a credit line to the material. If material is not included in the article's Creative Commons licence and your intended use is not permitted by statutory regulation or exceeds the permitted use, you will need to obtain permission directly from the copyright holder. To view a copy of this licence, visit http://creativecommons.org/licenses/by/4.0/. The Creative Commons Public Domain Dedication waiver (http://creativeco mmons.org/publicdomain/zero/1.0/) applies to the data made available in this article, unless otherwise stated in a credit line to the data. 
have suffered from COPD, which was responsible for about 3.2 million deaths worldwide, and COPD was the fifth leading cause of loss of disability-adjusted life years (DALYs) in 2017 [2]. COPD affected around $13.6 \%-13.7 \%$ of adults aged 40 or older in China according to two recent investigations $[3,4]$, with a mortality rate of 68 per 100,000 people in 2017, representing the fourth leading cause of DALYs in China [5].

Obstructive sleep apnea (OSA) is another common respiratory disease, which is characterized by recurrent closure of the upper airway during sleep and is usually associated with COPD. The coexistence of OSA and COPD has been described as "overlap syndrome" [6]. The prevalence of overlap syndrome varies among geographic regions and populations [7]. Shawon et al. [7] reported incidences of COPD coexisting with OSA ranging from $2.9 \%$ to $65.9 \%$ in a systematic review. Overlap syndrome has more serious adverse effects on the quality of life in patients with COPD [7, 8]. Because of their similar pathophysiological effects, especially in terms of hypoxia and systemic inflammation, the simultaneous occurrence of COPD and OSA has more severe nocturnal hypoxemic and hypercarbia effects than either COPD or OSA alone, and is more likely to be complicated with cardiovascular diseases $[7,9]$. Overlap of these two conditions can also reduce daytime oxygen saturation and quality of life-related scores, and increase the frequencies of acute exacerbation, comorbidity, economic burden and mortality due to COPD $[7,10,11]$. However, continuous positive airway pressure treatment can reduce the risk of COPD exacerbation and prolong patient survival $[7,11,12]$. The identification and timely treatment of overlap syndrome in patients with COPD therefore can help to improve patient prognosis. Many studies have investigated the possible predictive factors of overlap syndrome; however, the findings have been inconsistent. Peripheral edema and emphysema have been reported to predict OSA [13, 14], but the predictive values of age, sex, body mass index (BMI), neck circumference, and smoking status remained controversial $[15,16]$. Further investigations are, therefore, needed to clarify the roles of these factors in predicting OSA. Furthermore, a better understanding of the important risk factors and clinical outcomes of patients with overlap syndrome in different geographical areas would help the relevant health authorities to implement targeted intervention strategies [17]. We conducted a crosssectional community-based study in China to clarify the prevalence, clinical characteristics, risk factors of COPD with OSA, and the relationship between airflow limitation in COPD and severity of OSA.

\section{Methods}

\section{Study design}

This was a cross-sectional study conducted in 11 regions of the Xuzhou area in eastern China from December 2018 to December 2019. The aim was to investigate the prevalence of OSA in patients with COPD and to identify its predictors. Sampling was carried out by multistage cluster random sampling from all 11 regions in the study area. In the first stage, three community health service centers were selected from each region by cluster random sampling; in the second stage, three community health service stations were selected by cluster random sampling from each selected community health service center; and in the final stage, patients with COPD who met the inclusion criteria and who were registered at the health service stations were enrolled, according to their medical records. Information on all the variables was collected by trained investigators by face-to-face interview on the day of the participants' regular medical appointments at the health centers.

\section{Participants}

Patients diagnosed with COPD with severity classified according to the 2017 Global Initiative for Chronic Obstructive Lung Disease (GOLD) guidelines were eligible [1]. Exclusion criteria were patients who refused to participate in the study, patients who failed to perform pulmonary function test due to acute exacerbation or severe illness, patients unable to tolerate or who refused whole-night polysomnography, patients disqualified from polysomnography, and pregnant women (Fig. 1).

The study protocol was approved by the medical ethics committee of Xuzhou Center for Disease Control and Prevention (number: 2012010). All patients signed written informed consent, underwent pulmonary function tests and polysomnography, and provided the required information. The trial was conducted according to the 2000 revised version of the Helsinki Declaration. The study followed the STROBE (Strengthening the Reporting of Observational Studies in Epidemiology) guidelines for observational studies [18].

\section{Spirometry}

Spirometry was performed at health centers using a portable spirometer (Medikro PRO, Finland). The pulmonary function testing was performed in a comfortable and quiet environment. Before the test, the subjects were explained the purpose of the test and the essentials of the action, and asked whether they met the exclusion criteria of pulmonary function test. The pulmonary instrument was adjusted and calibrated the parameters before each measurement. The basic 


\section{Patients with COPD who registered in community health stations}

were recruited $(n=1026)$

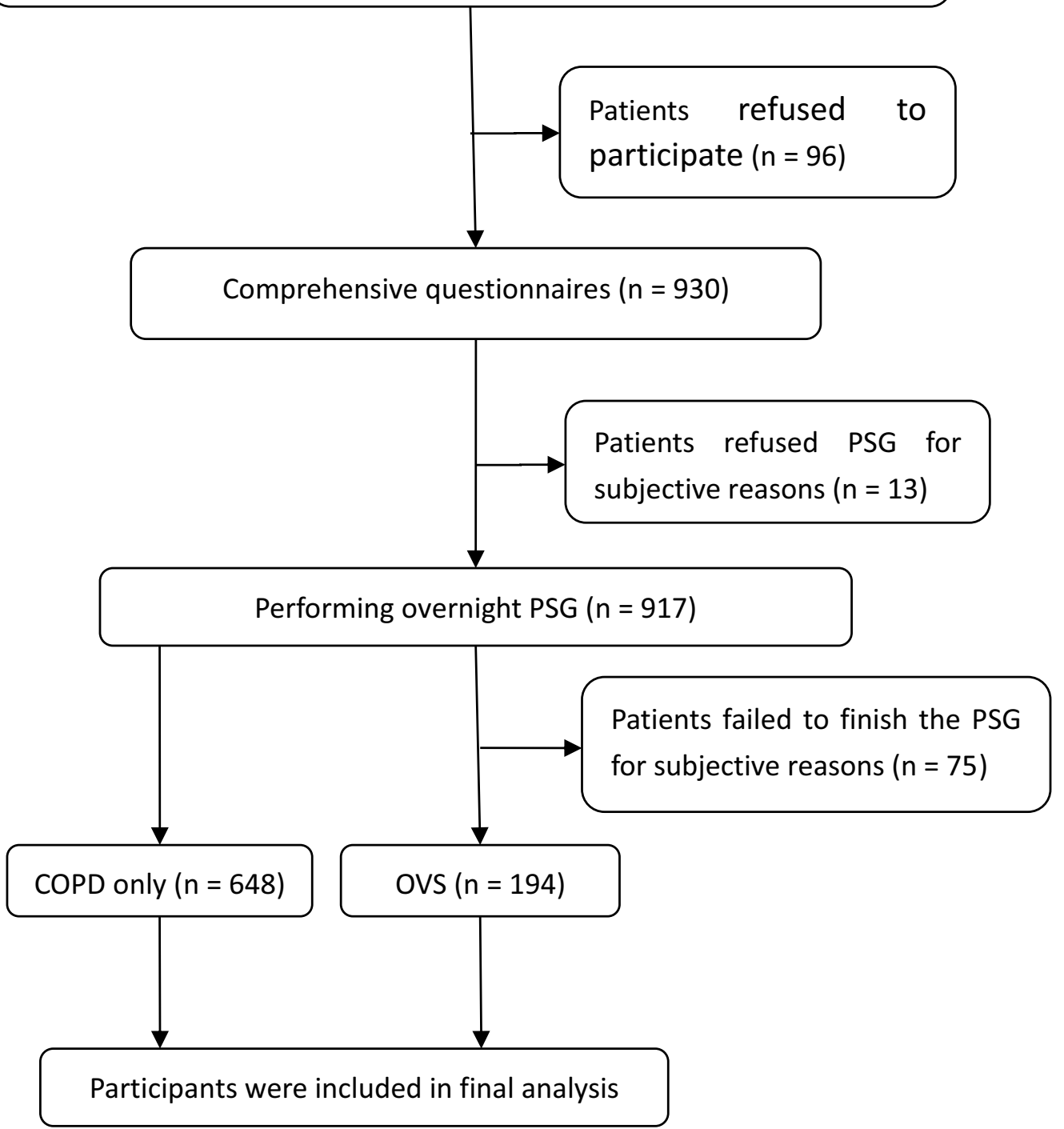

Fig. 1 Flowchart of the study design

pulmonary function and lung function after bronchodilator test were measured by a unified method. After completing the basic test, every person used salbutamol aerosol 400ug. A 15-min interval after the bronchodilator test, all subjects were measured the pulmonary function. With the automated device, 3 readings were taken at $1 \mathrm{~min}$ intervals. The difference between FEV1 and FVC were less than $200 \mathrm{ml}$, and PEF was less than $0.67 \mathrm{~L} / \mathrm{s}$. COPD was defined according to GOLD guidelines according to the ratio of post bronchodilator forced expiratory volume (FEV) in $1 \mathrm{~s}$ $\left(\mathrm{FEV}_{1}\right)$ to forced vital capacity $(\mathrm{FVC})<70 \%[1]$.

\section{Monitoring with polysomnography and OSA severity}

Participants who met the diagnostic criteria for COPD were monitored at home for at least $7 \mathrm{~h}$ at night using a comprehensive portable polysomnography machine (PSM-100A, Sealand, Chengdu, China). The data including snoring, nasal airflow, thoracoabdominal breathing exercise, blood oxygen saturation and disorder index by the monitor were automatically recorded and analyzed, 
and then manually corrected the next day. The results were recorded by two skilled sleep technicians, following standard criteria [19]. OSA was defined as an apneahypopnea index $(\mathrm{AHI}) \geq 5$ events per hour. OSA's severity was categorized based on the AHI as normal $(<5)$, mild $(5-14.9)$, moderate (15-29.9) and severe $(\geq 30)[20]$.

\section{COPD clinical outcomes and other variables}

The clinical outcomes of patients with COPD included dyspnea and health status. Dyspnea was measured using the modified Medical Research Council mMRC dyspnea scale [21] with a score of $0-4$ points, with a higher score indicating more-severe dyspnea. Health status was measured using the COPD assessment test (CAT) [22], which included a total of eight items, each with a score of $0-5$, giving a total score of $0-40$, with a higher score indicating a poorer health status. OSA was measured using the STOP-Bang questionnaire (SBQ), including eight questions with 'yes' ( 1 point) or 'no' ( 0 points) answers, with a total score $\geq 3$ indicating OSA [23].

Depression and anxiety were screened and measured using the 14-item Hospital Anxiety and Depression Scale (HADS), including seven items relating to anxiety (HADS-A) and the other seven relating to depression (HADS-D). The overall score ranged from 0 to 21, with a score $\geq 8$ on a subscale indicating possible HADS-A or HADS-D, respectively [24]. Comorbidities were assessed according to the Charlson Comorbidity Index (CCI) [25], which included 17 common concomitant medical conditions, as follows: (1) 1 point: myocardial infarction, heart failure, peripheral vascular disease, cerebrovascular disease, dementia, chronic lung disease, connective tissue disease, peptic ulcer, mild liver disease and diabetes without organ damage; (2) 2 points: hemiplegia, moderate to severe kidney disease, diabetes mellitus with organ injury, solid tumor in any part, malignant lymphoma and leukemia; (3) 3 points: moderate and severe liver disease; and (4) 6 points: metastatic solid tumor, acquired immune deficiency syndrome. Age was also scored as 1 point for 50-59 years old, 2 points for 60-69 years old, and 3 points for $\geq 70$ years old. The CCI score plus age score was taken as the total score. In this study, cases of hypertension, coronary heart disease, pulmonary heart disease, and diabetes were separately counted again.

\section{Other demographic variables}

Independent variables included patients with COPD and OSA/COPD overlap syndrome. Subject-specific variables collected using a self-designed questionnaire included sex, age, BMI, neck circumference, course of disease, smoking index, number of acute exacerbation in the past year, and number of acute exacerbations requiring hospitalization. BMI was calculated by dividing body weight in kilograms by height in meters squared. Smoking index was equal to the number of cigarettes per day multiplied by the number of years of smoking.

\section{Sample-size calculation}

Assuming an estimated $40.0 \%$ of participants with OSA/ COPD overlap syndrome [9] with an admissible error of $10 \%$, power of $90 \%$, and alpha of 0.05 , and allowing for a refusal rate of $15 \%$, we calculated that a minimum of 663 subjects needed to be enrolled. The COPD registry system covered all communities in the Xuzhou area. A total of 29,800 patients with COPD were registered in 2950 health service stations from 211 community health service centers, with about 10 patients with COPD in each community health service station.

\section{Primary and secondary outcomes}

The primary outcomes were influence factors for overlap syndrome. The secondary outcome was the prevalence of overlap syndrome in patients with COPD.

\section{Statistical analysis}

Risk factors for COPD with coexisting OSA were analyzed using SPSS 17.0(SPSS Inc., Chicago, USA). Participants were divided into two groups according to the results of monitoring with polysomnography. The COPD group comprised patients with an $\mathrm{AHI}<15$ events per hour, and the COPD-OSA group included patients with an $\mathrm{AHI} \geq 15$ events per hour. Categorical data were expressed as number of cases (percentage) and analyzed using $X^{2}$ tests. Measured data were tested for normality, and data conforming to a normal distribution were expressed as mean \pm standard deviation, with $t$-tests for pairwise comparisons. Data that did not conform to a normal distribution were expressed as median (interquartile range), and differences were compared by Mann-Whitney U tests. Correlations between two continuous variables were analyzed by Spearman's correlation analysis.

Multivariate logistic regression analysis (dependent variables: 0 , patients with COPD without risk of OSA symptoms $(\mathrm{AHI}<15$ events per hour); 1 , patients with COPD with risk of OSA symptoms (AHI $\geq 15$ events per hour)) were performed to assess the likelihood of risk of OSA versus no risk of OSA in patients with COPD, in the presence of exposure variables including age, sex, $\mathrm{BMI}$, neck circumference, smoking index, $\mathrm{FEV}_{1}, \mathrm{FEV}_{1} \%$ of expected value, FEV1 (\%predicted) $<50 \%, \mathrm{FEV}_{1} / \mathrm{FVC}$, CAT score, Epworth sleepiness scale (ESS) score, SBQ score, HADS-A score, HADS-D score, hypertension, coronary heart disease, and diabetes. $\mathrm{FEV}_{1}, \mathrm{FEV}_{1} \%$ of expected value, $\mathrm{FEV}_{1} / \mathrm{FVC}$, SBQ, HADS-A, and HADS$D$ were assigned a value of 1 if they were greater than the 
average and 0 if they were less than the average. $\mathrm{FEV}_{1} \%$ accounting for a predicted value $<50 \%$ was also assigned a score of 1 and $\mathrm{FEV}_{1} \%$ accounting for a predicted value $\geq 50 \%$ was assigned a score of 0 . All tests were two sided. A $p$-value $<0.05$ was considered statistically significant.

\section{Results}

\section{Characteristics of study participants and OSA symptoms} in the participants

A flowchart of the study design and process is shown in Fig. 1. A total of 1026 patients with COPD registered in 99 community health stations were selected for this observational study. Based on the design principles, 184 subjects were excluded, including 96 who refused to participate, 47 without pulmonary function tests because of acute exacerbation or serious condition, 28 who were unable to tolerate whole-night polysomnography, and 13 who refused to be monitored by polysomnography. A total of 842 patients were therefore included in the final analysis (606 males (72\%) and 236 females (28\%), average age $63 \pm 8$ years). A total of $66.0 \%$ of the 842 patients completed the study with an $\mathrm{AHI} \geq 5$ events per hour.

\section{Characteristics of participants with and without risk of OSA symptoms}

The general characteristics of the patients according to AHI are shown in Table 1. There were no significant differences in age, sex, smoking index, number of acute exacerbations in the year before admission, hospital frequency, mMRC score, and cor pulmonale between the COPD group and COPD-OSA group (all $p>0.05$ ). BMI, neck circumference, FEV1, FEV1 (\%predicted), FEV1/ FVC, AHI, CAT, ESS, SBQ, HADS-A, and HADS-D scores, and the incidences of hypertension, coronary heart disease, and diabetes were all significantly higher and the proportion of severe COPD [(FEV1 (\%predicted) $<50 \%$ ] was significantly lower in the COPD-OSA group compared with the COPD group (all $p<0.05$ ).

\section{Correlations of $\mathrm{AHI}$ and risk factors}

Analysis of the correlations between AHI and variables revealed significant differences between the groups in terms of BMI, neck circumference, $\mathrm{FEV}_{1}$, percentage of $\mathrm{FEV}_{1}$ accounting for predicted value, percentage of $\mathrm{FEV}_{1}$ accounting for predicted value $<50 \%$, CAT, ESS, SBQ, HADS-A, and HADS-D scores, hypertension, coronary heart disease, and diabetes (all $p<0.05$ ). There was a significant negative correlation between $\mathrm{AHI}$ and $\mathrm{FEV}_{1} \%$ accounting for predicted value $<50 \%(p<0.05)$ (Table 2$)$.
Independent predictors for risk of OSA symptoms in COPD The risk factors for coexisting OSA in patients with COPD were analyzed by univariate logistic regression analysis. COPD coexisting with $\mathrm{OSA}(\mathrm{AHI} \geq 15$ events per hour) was taken as the dependent variable and assigned a score of 1 and $\mathrm{AHI}<15$ events per hour was assigned a score of 0 . Age, BMI, neck circumference, $\mathrm{FEV}_{1}, \mathrm{FEV}_{1} \%$ of expected value, $\mathrm{FEV}_{1}$ (\%predicted) $<50 \%$, CAT, ESS, SBQ, HADS-A, HADS-D, hypertension, coronary heart disease, and diabetes were taken as independent variables and analyzed one by one by univariate logistic regression. BMI, neck circumference, $\mathrm{FEV}_{1}$, CAT, ESS, SBQ, HADS-A, HADS-D, hypertension, coronary heart disease, and diabetes were all shown to be risk factors for COPD combined with OSA (all $p<0.05$ ) (Table 3). The risk of OSA in patients with severe $\mathrm{COPD}\left[\mathrm{FEV}_{1}\right.$ (\%predicted) $<50 \%$ ] was lower than that in patients with mild and moderate $\mathrm{COPD}\left[\mathrm{FEV}_{1}\right.$ (\%predicted $) \geq 50 \%](\beta=-0.621$, odds ratio $(\mathrm{OR})=0.551,95 \%$ confidence interval (CI): 0.412-0.691, $p<0.001$ ) (Table 3). Patients with COPD and coexisting OSA had poorer ESS, SBQ, HADS-A, HADS-D, and CAT scores, and more hypertension, coronary heart disease, and diabetes.

We also analyzed the risk factors for COPD coexisting with OSA by multivariate logistic regression analysis. BMI, neck circumference, CAT, ESS, HADS-A, HADS$\mathrm{D}$, and CCI scores, and $\mathrm{FEV}_{1}$ (\%predicted) $<50 \%$ o were used as independent variables in multivariate logistic regression using the forced entry method, after adjusting for age, sex, smoking index and $\mathrm{FEV}_{1}$. BMI $(\beta=0.153$, $\mathrm{OR}=1.165,95 \% \mathrm{CI}: 1.094-1.242, p<0.001)$, neck circumference, CAT, ESS, SBQ, HADS-A, HADS-D, and $\mathrm{CCI}$ were all identified as independent risk factors for OSA in patients with COPD. Hypertension and diabetes were also identified as independent risk factors of OSA in patients with COPD after adjusting for age, sex, smoking index $\mathrm{FEV}_{1}$, BMI, CAT, ESS, HADS-A, HADS-D, and percentage of $\mathrm{FEV}_{1}$ accounting for $<50 \%$ of the predicted values. SBQ was shown to be an independent risk factor after adjusting for age, smoking index, $\mathrm{FEV}_{1}, \mathrm{CAT}$, ESS, HADS-A, HADS-D, CCI, and $\mathrm{FEV}_{1}$ (\%predicted) $<50 \%$. The risk of OSA in patients with severe COPD $\left[\mathrm{FEV}_{1}\right.$ (\%predicted) $<50 \%]$ was lower than that in patients with mild and moderate COPD $(\beta=-0.549$, OR $=0.578,95 \%$ CI: 0.392-0.782, $p=0.045$ ) (Table 4 ).

\section{Correlation between airflow limitation of COPD and severity of $O S A$}

We analyzed the relationship between the degree of airflow restriction according to GOLD grading and the severity of OSA according to AHI. There were significant differences in the severity of airflow restriction in 
Table 1 Comparison of general characteristics of patients between two groups (Mean \pm SD)

\begin{tabular}{|c|c|c|c|c|c|c|c|c|}
\hline \multirow[t]{2}{*}{ Variables } & \multicolumn{3}{|l|}{$\begin{array}{l}\text { COPD group } \\
(N=648)\end{array}$} & \multicolumn{3}{|l|}{$\begin{array}{l}\text { COPD } \\
\text { overlap OSA } \\
\text { group }(N=194)\end{array}$} & \multirow[t]{2}{*}{$\mathrm{x}^{2} / \mathrm{t}$ value } & \multirow[t]{2}{*}{$P$} \\
\hline & $\mathrm{AHI}<5$ events $/ \mathrm{h}$ & $\begin{array}{l}5 \text { events / } \\
h \leq A H I<15 \\
\text { events / } h\end{array}$ & Total & $\begin{array}{l}15 \text { events } \\
h \leq A H I<30 \\
\text { events / } h\end{array}$ & $\begin{array}{l}\mathrm{AHI} \geq 30 \text { events } \\
/ \mathrm{h}\end{array}$ & Total & & \\
\hline Gender (male,\%) & $200(69.93 \%)$ & 253(69.89\%) & $453(69.91 \%)$ & $87(70.73 \%)$ & $54(76.06 \%)$ & $141(72.68 \%)$ & 0.427 & 0.513 \\
\hline Age y (mean $\pm S D$ ) & $62 \pm 7$ & $64 \pm 9$ & $63 \pm 8$ & $63 \pm 9$ & $64 \pm 9$ & $62 \pm 7$ & 1.57 & 0.117 \\
\hline $\begin{array}{l}\text { BMI }\left(\mathrm{kg} / \mathrm{m}^{2}\right) \\
(\text { mean } \pm \mathrm{SD})\end{array}$ & $21 \pm 3$ & $22 \pm 4$ & $22 \pm 4$ & $23 \pm 4$ & $24 \pm 4$ & $24 \pm 4$ & -6.11 & $<0.001$ \\
\hline $\begin{array}{l}\text { Neck circum- } \\
\text { ference }(\mathrm{cm}) \\
\text { (mean } \pm \text { SD) }\end{array}$ & $36.5 \pm 2.2$ & $37.3 \pm 3.1$ & $37.0 \pm 2.6$ & $37.5 \pm 35$ & $38.6 \pm 3.6$ & $38.1 \pm 3.5$ & 3.97 & $<0.001$ \\
\hline $\begin{array}{l}\text { Smoking index } \\
\text { (package year) }\end{array}$ & $32.5 \pm 27.8$ & $37.5 \pm 27.0$ & $35.5 \pm 27.5$ & $38.5 \pm 25.5$ & $40.5 \pm 22.6$ & $39.2 \pm 24.8$ & -1.68 & 0.093 \\
\hline $\begin{array}{l}\text { Smoke } \\
\text { status(never,\%) }\end{array}$ & $123(43.01 \%)$ & 133(36.74\%) & $248(38.27 \%)$ & $42(34.15 \%)$ & $25(35.21 \%)$ & $67(34.54 \%)$ & 5.53 & 0.06 \\
\hline $\begin{array}{l}\mathrm{FEV}_{1}(\mathrm{~L}) \\
(\text { mean } \pm \mathrm{SD})\end{array}$ & 1 & $1.1 \pm 0.8$ & $1.0 \pm 0.8$ & $1.2 \pm 1.0$ & $1.4 \pm 1.3$ & $1.3 \pm 1.1$ & -4.18 & $<0.001$ \\
\hline $\begin{array}{l}\mathrm{FEV}_{1} \% \text { of expected } \\
\text { value (mean } \pm \mathrm{SD} \text { ) }\end{array}$ & $42.0 \pm 28.5$ & $45.5 \pm 30.0$ & $44.5 \pm 29.5$ & $52.5 \pm 32.6$ & $60.0 \pm 39.5$ & $55.0 \pm 36.5$ & -4.11 & $<0.001$ \\
\hline $\begin{array}{l}\mathrm{FEV}_{1} \% \text { of predicted } \\
\text { value }<50 \%(\mathrm{n})\end{array}$ & 169(59.09\%) & 190(52.49\%) & $359(55.40 \%)$ & $51(41.46 \%)$ & $24(33.80 \%)$ & $75(38.66 \%)$ & 10.047 & 0.002 \\
\hline $\mathrm{FEV}_{1} / \mathrm{FVC}(\%)$ & $38.0 \pm 21.0$ & $40.0 \pm 20.0$ & $39.0 \pm 21.0$ & $43.0 \pm 23.0$ & $55.0 \pm 25.0$ & $49.0 \pm 240$ & -5.624 & $<0.001$ \\
\hline AHI (events / h) & $2.5 \pm 2.2$ & $9.1 \pm 5.2$ & $6.2 \pm 5.7$ & $19.8 \pm 7.3$ & $37.8 \pm 20.0$ & $26.7 \pm 14.7$ & -28.987 & $<0.001$ \\
\hline $\begin{array}{l}\text { Acute exacerba- } \\
\text { tion in the past } \\
\text { year (frequency) }\end{array}$ & $2.1 \pm 1.5$ & $2.2 \pm 2.1$ & $2.1 \pm 2.0$ & $2.1 \pm 2.0$ & $2.1 \pm 2.0$ & $2.0 \pm 2.1$ & 0.60 & 0.546 \\
\hline $\begin{array}{l}\text { Hospitalization } \\
\text { in the past year } \\
\text { (frequency) }\end{array}$ & $0.5 \pm 1.1$ & $1.3 \pm 2.2$ & $1.3 \pm 1.5$ & $1.2 \pm 2.1$ & $1.1 \pm 2.0$ & $1.2 \pm 2.0$ & 0.75 & 0.453 \\
\hline $\begin{array}{l}\text { mMRC scores } \\
(\text { mean } \pm \text { SD) }\end{array}$ & $2.0 \pm 0.4$ & $1.0 \pm 2.2$ & $1.5 \pm 1.3$ & $1.8 \pm 2.0$ & $1.5 \pm 1.3$ & $1.6 \pm 1.1$ & -0.97 & 0.331 \\
\hline $\begin{array}{l}\text { CAT scores } \\
\text { (mean } \pm \text { SD) }\end{array}$ & $14.7 \pm 6.5$ & $16.8 \pm 7.3$ & $15.9 \pm 7.2$ & $17.3 \pm 8.2$ & $19.2 \pm 8.4$ & $18.4 \pm 8.4$ & -4.08 & $<0.001$ \\
\hline $\begin{array}{l}\text { ESS scores } \\
\text { (mean } \pm S D)\end{array}$ & $4.1 \pm 4.0$ & $5.2 \pm 4.1$ & $5.1 \pm 4.0$ & $6.2 \pm 5.1$ & $8.1 \pm 9.0$ & $7.8 \pm 5.9$ & -7.32 & $<0.001$ \\
\hline $\begin{array}{l}\text { SBQ } \\
\text { scores(mean } \pm S D)\end{array}$ & $3.1 \pm 2.0$ & $4.4 \pm 3.2$ & $4.2 \pm 3.0$ & $5.5 \pm 4.0$ & $7.0 \pm 4.0$ & $6.0 \pm 4.0$ & -7.50 & $<0.001$ \\
\hline HADS-A scores & $4.5 \pm 3.2$ & $6.5 \pm 4.1$ & $5.7 \pm 3.8$ & $7.6 \pm 4.0$ & $10.5 \pm 7.5$ & $9.3 \pm 6.1$ & -9.92 & $<0.001$ \\
\hline HADS-D scores & $4.4 \pm 2.7$ & $6.3 \pm 4.3$ & $5.5 \pm 3.6$ & $7.2 \pm 4.5$ & $11.0 \pm 7.2$ & $9.5 \pm 6.4$ & -11.10 & $<0.001$ \\
\hline $\begin{array}{l}\mathrm{CCl} \text { scores } \\
\text { (mean } \pm \mathrm{SD})\end{array}$ & $2.0 \pm 1.0$ & $3.0 \pm 2.0$ & $2.7 \pm 1.4$ & $3.0 \pm 1.5$ & $4.0 \pm 2.0$ & $3.4 \pm 1.7$ & 0 & 1 \\
\hline Hypertension $(n, \%)$ & $71(24.83 \%)$ & 119(32.87\%) & $190(29.32 \%)$ & $52(42.28 \%)$ & $41(57.75 \%)$ & $93(47.94 \%)$ & 8.001 & 0.005 \\
\hline $\begin{array}{l}\text { Cor Pulmonale } \\
(n, \%)\end{array}$ & 15(5.24\%) & $22(6.08 \%)$ & $37(5.71 \%)$ & $9(7.32 \%)$ & $6(8.45 \%)$ & $15(7.73 \%)$ & 0.937 & 0.333 \\
\hline $\begin{array}{l}\text { Coronary heart } \\
\text { disease }(\mathrm{n}, \%)\end{array}$ & $22(7.69 \%)$ & $45(12.43 \%)$ & $67(10.34 \%)$ & 14(11.38\%) & $6(8.45 \%)$ & $20(10.31 \%)$ & 7.305 & 0.007 \\
\hline Diabetes (n,\%) & 15(5.24\%) & $61(16.85 \%)$ & $76(11.73 \%)$ & $24(19.51 \%)$ & $20(28.17 \%)$ & $44(22.68 \%)$ & 13.845 & $<0.001$ \\
\hline
\end{tabular}

Gender, FEV $1 \%$ of predicted value $<50 \%$, Hypertension, cor pulmonale,coronary heart disease and diabetes are presented as $\mathrm{n}$; other values are the mean with SD; COPD chronic obstructive pulmonary disease; OSA obstructive sleep apnea; SD standard deviation; BMI body mass index; FEV forced expiratory volume in $1 \mathrm{~s} ; F V C$ forced vital capacity; $A H I$ apnea-hypopnea index; $m M R C$ Modified British Medical Research Council; CAT COPD assessment test; ESS Epworth sleepiness scale; CCI Charlson comorbidity index; SBQ STOP-Bang; HADS-A Hospital Anxiety and Depression Scale for anxiety; HADS-D Hospital Anxiety and Depression Scale for depression

patients with COPD according to the distribution of AHI $(<5, \geq 5$ to $<15, \geq 15$ to $<30$, and $\geq 30$ events per hour) (Table 5). The proportion of $\mathrm{AHI}<5$ events per hour increased with increasing airflow restriction $(p<0.001)$, while the proportions of 15 to $<30$ and $\geq 30$ events per hour decreased with increasing 


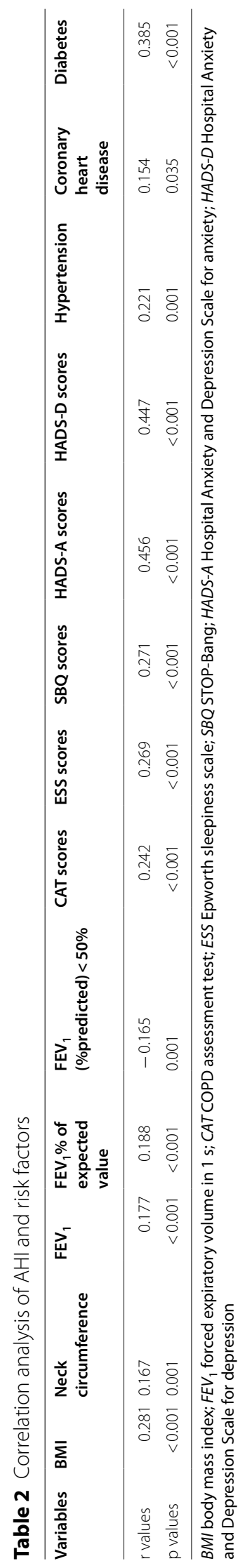


Table 3 Results of univariate logistic regression used to explore risk factors for COPD coexisting OSA (AHI> 15 times per hour)

\begin{tabular}{lrrrrl}
\hline Variables & $\boldsymbol{B}$ & Wald & $\boldsymbol{P}$ & OR & $\mathbf{9 5 \%} \mathrm{Cl}$ \\
\hline Age & 0.019 & 2.017 & 0.142 & 1.017 & $0.992 \sim 1.041$ \\
BMI $\left(\mathrm{kg} / \mathrm{m}^{2}\right)$ & 0.178 & 32.158 & $<0.001$ & 1.186 & $1.115 \sim 1.258$ \\
Neck circumference & 0.186 & 12.452 & $<0.001$ & 1.201 & $1.114 \sim 1.289$ \\
FEV $_{1}$ & 0.006 & 2.457 & 0.047 & 1.009 & $1.000 \sim 1.019$ \\
FEV $_{1} \%$ of expected & 0.025 & 0.141 & 0.463 & 0.958 & $0.841 \sim 1.075$ \\
value & & & & & \\
FEV ${ }_{1}$ (\%pre- & -0.621 & 7.412 & 0.041 & 0.551 & $0.412 \sim 0.691$ \\
dicted) $<50 \%$ & & & & & \\
CAT scores & 0.201 & 32.263 & $<0.001$ & 1.305 & $1.121 \sim 1.490$ \\
ESS scores & 0.137 & 9.524 & $<0.001$ & 1.128 & $1.074 \sim 1.182$ \\
SBQ scores & 0.223 & 17.623 & $<0.001$ & 1.311 & $1.125 \sim 1.498$ \\
HADS-A scores & 0.243 & 29.132 & $<0.001$ & 1.324 & $1.131 \sim 1.517$ \\
HADS-D scores & 0.251 & 30.541 & $<0.001$ & 1.301 & $1.122 \sim 1.481$ \\
Hypertension & 0.351 & 35.022 & 0.029 & 2.011 & $1.551 \sim 2.470$ \\
Coronary heart disease & 0.133 & 5.851 & 0.045 & 1.148 & $1.006 \sim 1.291$ \\
Diabetes & 0.402 & 37.112 & $<0.001$ & 2.055 & $1.442 \sim 2.669$ \\
\hline
\end{tabular}

Overlap syndrome (AHI $>15$ times per hour) was considered as the dependent variable and age, $\mathrm{BMI}$, neck circumference, $\mathrm{FEV}_{1}, \mathrm{FEV}_{1} \%$ of expected value, $\mathrm{FEV}_{1}$ (\%predicted) $<50 \%$, CAT score, ESS score, SBQ scores, HADS-A scores, HADS-D scores, hypertension, coronary heart disease and diabetes as independent variables. $B M I$ body mass index; $F E V_{1}$ forced expiratory volume in $1 \mathrm{~s}$; CAT COPD assessment test; ESS Epworth sleepiness scale; SBQ STOP-Bang; HADS-A Hospital Anxiety and Depression Scale for anxiety; HADS-D Hospital Anxiety and Depression Scale for depression

Table 4 Multivariate logistic regression analysis of risk factors for COPD coexisting OSA (AHI > 15 times per hour)

\begin{tabular}{lrrrrl}
\hline Variables & $\boldsymbol{\beta}$ & Wald & $\boldsymbol{P}$ & OR & $\mathbf{9 5 \%} \mathbf{C l}$ \\
\hline BMI $\left(\mathrm{kg} / \mathrm{m}^{2}\right)$ & 0.161 & 26.794 & $<0.001$ & 1.175 & $1.104 \sim 1.251$ \\
Neck circumference & 0.101 & 4.251 & $<0.001$ & 1.099 & $1.013 \sim 1.211$ \\
FEV $_{1}$ & 0.023 & 2.086 & 0.149 & 1.023 & $0.991 \sim 1.057$ \\
FEV $_{1}(\%$ pre- & -0.549 & 5.893 & 0.045 & 0.578 & $0.392 \sim 0.782$ \\
dicted) $<50 \%$ & & & & & \\
CAT scores & 0.187 & 30.154 & $<0.001$ & 1.195 & $1.112 \sim 1.288$ \\
ESS scores & 0.118 & 7.667 & $<0.001$ & 1.113 & $1.052 \sim 1.177$ \\
SBQ scores & 0.188 & 13.866 & $<0.001$ & 1.206 & $1.119 \sim 1.301$ \\
HADS-A & 0.201 & 27.956 & $<0.001$ & 1.275 & $1.126 \sim 1.432$ \\
HADS-D & 0.198 & 28.012 & $<0.001$ & 1.243 & $1.120 \sim 1.401$ \\
Hypertension & 0.309 & 30.442 & 0.037 & 1.831 & $1.357 \sim 2.321$ \\
Coronary heart disease & 0.111 & 3.458 & 0.053 & 1.117 & $0.999 \sim 1.249$ \\
Diabetes & 0.311 & 34.521 & $<0.001$ & 1.852 & $1.421 \sim 2.312$ \\
\hline
\end{tabular}

Overlap syndrome (AHI $>15$ times per hour) was considered as the dependent variable and age, $\mathrm{BMI}$, neck circumference, $\mathrm{FEV}_{1}, \mathrm{FEV}_{1}$ (\% predicted) $<50 \%$, CAT score, ESS score, SBQ scores, HADS-A scores, HADS-D scores, hypertension, coronary heart disease and diabetes as independent variables. BMI body mass index; FEV ${ }_{1}$ forced expiratory volume in $1 \mathrm{~s}$; CAT COPD assessment test; ESS Epworth sleepiness scale; SBQ STOP-Bang; HADS-A Hospital Anxiety and Depression Scale for anxiety; HADS-D Hospital Anxiety and Depression Scale for depression. airflow restriction (both $p<0.001$ ). Compared with COPD patients with mild and moderate airflow restriction $\left[\mathrm{FEV}_{1}(\%\right.$ predicted $\left.) \geq 50 \%\right]$, the proportion of $\mathrm{AHI}<5$ events per hour was higher in COPD patients with severe airflow restriction $\left[\mathrm{FEV}_{1}(\%\right.$ predicted $\left.)<50 \%\right](p<0.001)$, while the proportion of $\mathrm{AHI} \geq 30$ events per hour was lower in COPD patients with severe airflow restriction $\left[\mathrm{FEV}_{1}(\%\right.$ predicted $\left.)<50 \%\right](p<0.001)$.

\section{Discussion}

In this cross-sectional study, we assessed the prevalence, possible predictors, and associated comorbidities of overlap syndrome in patients with COPD.

The prevalence of COPD coexisting with OSA was $66.0 \%$, based on a threshold $\mathrm{AHI} \geq 5$ events per hour, while $23 \%$ had an $\mathrm{AHI} \geq 15$ events per hour. Compared with COPD patients without OSA, patients in the COPDOAS group (AHI $\geq 15)$ had significantly higher BMI, $\mathrm{AHI}$, and a larger neck circumference; however, there were no significant differences in sex, age, and tobacco use between the two groups. Anxiety, depression, hypertension, and diabetes mellitus were more common in participants with overlap syndrome. The quality of life was also poorer in patients with overlapping symptoms, indicated by higher CAT, CCI, and ESS scores. SBQ showed a weak correlation with $\mathrm{AHI}$, and overlap syndrome was more frequent in patients with mild and moderate, compared with severe COPD.

The prevalence of overlap syndrome among patients with COPD in our study was $66 \%$. Steveling et al. reported a prevalence of OSA in patients with COPD of $35 \%$ based on an AHI of $>5$ events per hour [26], while $\mathrm{Hu}$ et al. reported that $68.18 \%$ of COPD patients had coexisting OSA $(\mathrm{AHI} \geq 5)$ [27]. In a meta-analysis by Shawon et al., $2.9 \%-65.9 \%$ of patients with COPD had coexisting OSA [7]. The reported prevalence of OSA in patients with COPD thus varies widely, due to different methodologies, diagnostic definitions, and demographic characteristics [27]. However, another survey of inpatients in tertiary hospitals in China found that $77.7 \%$ of COPD patients had OSA [28], indicating that overlap syndrome was common among COPD patients in China. These results suggest that family doctors should screen COPD patients for OSA, to improve their quality of life.

The current results showed that BMI and neck circumference were significant predictors for OSA, consistent with other reports [26-29]. This might be because trunk obesity can reduce chest wall compliance and respiratory muscle strength, resulting in ventilation disturbances and ventilation perfusion mismatch [30]. In addition, individuals with larger necks have increased subcutaneous and visceral fat, resulting in crowding of the tonsils, uvula, palatopharyngeal arch, and pharyngeal lateral 
Table 5 Correlation between the degree of airflow limitation in COPD (GOLD classification) and the severity of OSA (n, \%)

\begin{tabular}{llllll}
\hline GOLD classification & Cases $(\mathbf{n}=\mathbf{8 4 2})$ & $\begin{array}{l}\mathbf{A H I}<\mathbf{5} \text { times } / \mathbf{h} \\
(\mathbf{n}=\mathbf{2 8 6})\end{array}$ & $\begin{array}{l}\mathbf{5} \text { times } / \mathbf{h} \leq \mathbf{A H I}<\mathbf{1 5} \\
\text { times } / \mathbf{h}(\mathbf{n}=\mathbf{3 6 2})\end{array}$ & $\begin{array}{l}\mathbf{1 5} \text { times } / \mathbf{h} \leq \mathbf{A H I}<\mathbf{3 0} \\
\text { times } / \mathbf{h}(\mathbf{n}=\mathbf{1 2 3})\end{array}$ & $\begin{array}{l}\mathbf{A H I} \geq \mathbf{3 0} \\
\mathbf{t i m e s} / \mathbf{h} \\
(\mathbf{n}=\mathbf{7 1})\end{array}$ \\
\hline I & & $19(6.64 \%)$ & $49(13.54 \%)$ & $22(17.89 \%)$ & $20(28.17 \%)$ \\
II & $110(13.06 \%)$ & $94(32.87 \%)$ & $148(40.88 \%)$ & $47(38.21 \%)$ & $31(43.66 \%)$ \\
III & $320(38.00 \%)$ & $124(43.36 \%)$ & $127(35.08 \%)$ & $38(30.89 \%)$ & $15(21.13 \%)$ \\
IV & $304(36.10 \%)$ & $49(17.13 \%)$ & $38(10.50 \%)$ & $16(13.01 \%)$ & $5(7.04 \%)$ \\
$X^{2}$ value & $108(12.83 \%)$ & 29.247 & 4.363 & 3.652 & 21.035 \\
Pvalue & - & $<0.001$ & 0.225 & 0.302 & $<0.001$ \\
\hline
\end{tabular}

AHI apnea-hypopnea index;

cord, leaving a narrow gap for airflow and leading to variety of whistling sounds [31, 32]. Peppard and co-workers reported that a $10 \%$ increase in weight could lead to a $32 \%$ increase in AHI, and a $10 \%$ decrease in weight resulted in a $26 \%$ decrease in AHI scores [33]. The sex ratio and age were similar in patients with COPD with and without OSA in the current study, possibly because COPD and OSA tend to occur in older men in China [27, 28, 34]. In contrast to other reports however $[11,26]$, there were no significant differences in mMRC scores, number of acute exacerbations in the year before admission, frequency of hospitalization, proportion of coronary heart disease, and cor pulmonale between COPD patients with and without OSA in the current study. This may be because some information (e.g. mMRC, number of acute exacerbations, etc.) depended on subjective answers by the patients, which could lead to missing reports. A previous study found a missing report rate for acute exacerbation in COPD patients of $>43.0 \%$ [35].

We analyzed the risk of OSA in patients with COPD by multiple logistic regression analysis after adjusting for age, sex, BMI, smoking index, and other confounding factors, and showed that hypertension and diabetes were independent risk factors in patients with COPD with coexisting moderate to severe OSA, consistent with other reports $[27,34,36]$. A previous study found that patients with overlap syndrome had more comorbidities, including hypertension and diabetes [30,34, 37]. Hypertension is the most frequently occurring comorbidity, while diabetes also damages lung function [38].

Multiple regression analysis showed that patients with COPD and coexisting OSA had higher CAT, ESS, CCI, and SBQ scores compared with patients with COPD alone. These findings were in line with previous studies that showed positive relationships between OSA and CAT, ESS, CCI, and SBQ scores in patients with COPD $[28,39]$. This suggested that patients with COPD overlapping with OSA had more-severe clinical symptoms, more-limited daily activities, more complications, and poorer sleep quality and quality of life. Although our findings suggested that the SBQ could be used for OSA screening, hypertension and male sex were the main contributory factors, while BMI and neck circumference were less important. This may be related to the generally low BMI of individuals in China [40]. Moreover COPD is a chronic consumptive disease and patients therefore tend to have a low BMI, especially patients with advanced disease [41], which could potentially protect against OSA. But, as a matter of fact, recent studies showed that OSA was more common in COPD patients with low BMI [42]. Soler et al. confirmed that COPD patients with a $\mathrm{BMI} \geq 25 \mathrm{~kg} / \mathrm{m}^{2}$ had a higher risk of OSA [29]. A South Korean clinical study showed that the accuracy of SBQ was not affected after removing the items 'fatigue' and 'neck circumference' [43], suggesting that the SBQ needs to be further optimized for Asian populations, including modifying or removing the scores for BMI and neck circumference for OSA screening in patients with COPD.

Multiple regression analysis also identified HADS-A and HADS-D scores as independent predictors for OSA in patients with COPD, in accordance with a previous study [37]. Heinzer et al. found that an AHI $>20.6$ events per hour of sleep was independently associated with the presence of depression [44]. Numerous studies have examined the interaction between smoking and overlap syndrome, but the results are controversial, with some studies finding a positive relationship [10, 11, 26], while other studies suggested no such relationship [27-29]. Our current results support the latter findings. Although smoking has a pathogenic effect on both COPD and OSA $[1,45]$, we found no interaction effect on overlap syndrome in patients with COPD in the current study. This may be because smoking resulted in homogenously distributed emphysema, regardless of the severity of smoking [46], and emphysema severity had a protective role for OSA [47].

We found a correlation between COPD severity and OSA. Compared with patients with COPD alone, 
patients with COPD plus OSA had higher $\mathrm{FEV}_{1}$, $\mathrm{FEV}_{1} \%$ of predicted value, and $\mathrm{FEV}_{1} / \mathrm{FVC}$, and a lower proportion of severe COPD $[26-28,39]$. The incidence of OSA increased with increasing airflow restriction in COPD patients with $\mathrm{AHI}<5$ events per hour, and decreased with increasing airflow restriction in COPD patients with AHI $>30$ events per hour. Compared with patients with mild and moderate airflow restriction, the proportion of $\mathrm{AHI}<5$ events per hour was higher and the proportion of $\mathrm{AHI}>30$ events per hour was lower in patients with severe airflow restriction. $\mathrm{FEV}_{1} \%$ accounting for the predicted value $<50 \%$ was assigned a value of 1 as an independent variable in univariate logistic regression analysis, and the results showed that patients with severe COPD had a lower risk of OSA than those with mild and moderate COPD, after adjusting for age, smoking, CCI, and $\mathrm{FEV}_{1}$. A previous study confirmed that hyperinflation had a potential protective effect against OSA in patients with COPD [42, 48]. Lung hyperinflation could prevent the occurrence of OSA by increasing the caudal stretch of the trachea and reducing the critical closing pressure of the upper airway during sleep [13, 49]. Krachman et al. [14]. used quantitative chest computed tomography to evaluate the percentage of emphysema and the degree of gas entrapment in patients with COPD coexisting OSA, and showed that the percentage of emphysema and the degree of gas entrapment were significantly negatively correlated with AHI, indicating the importance of lung volume in maintaining the opening of the upper respiratory tract. Overinflation thus had a protective effect against OSA, and might be a mechanism reducing the risk of OSA in patients with severe COPD.

It was previously shown that COPD patients with overlapping OSA had some independent risk factors; however, the risk of OSA was lower in patients with severe COPD had not been studied. Our study shows that OSA is common in patients with COPD in pulmonary outpatient clinics. In addition, the strengths of this study included the use of a community-based multistage sampling design, large sample size, and random cluster sampling. In addition, all diagnoses of OSA in COPD patients were established by overnight polysomnography which is the gold standard for diagnosing OSA. However, the study also had several limitations. It was a cross-sectional study, and it was therefore not possible to infer any causal relationships. Furthermore, the sample of subjects was not representative of China as a whole. The classifications of OSA, COPD, and overlap syndrome were based on self-reported interview (questionnaire) data, and were therefore subject to recall problems, misunderstanding of the question, and a variety of other factors. In addition, certain medications used to treat COPD, such as theophylline, may also have beneficial effects on OSA [50].
In conclusion, the results of this study showed that COPD patients with overlapping OSA had a poorer quality of life, more daytime sleepiness, and more hypertension than COPD patients without OSA. BMI and CAT and ESS scores were independent risk factors for COPD complicated with OSA. However, the risk of OSA was lower in patients with severe COPD. Our study suggests that OSA is common in patients with COPD in pulmonary outpatient clinics, and pulmonologists should thus consider screening for OSA symptoms in these patients.

\section{Acknowledgements \\ We thank Susan Furness, PhD, from Liwen Bianji, Edanz Editing China (www. liwenbianji.cn/ac), for editing the English text of a draft of this manuscript.}

\section{Authors' contributions}

P.Z, B.C., H.Q.L., P.P.C.,P.A.L., and Z.M.D. analyzed data; P.Z, B.C., H.Q.L., Y.N.Z., X.Z.., and P.A.L.interpreted results of experiments; T.L. and X.Z.. prepared figures and tables; P.Z, Y.N.Z., H.Q.L.,X.Z, and T.L.drafted manuscript;B.C., Z.M.D., and

P.A.L. edited and revised manuscript; P.Z, B.C.,and P.A.L.approved final version of manuscript; P.Z, B.C., and P.A.L. conception and design of research; B.C.,Y.N.Z and X.Z.performed experiments. All authors read and approved the final manuscript.

\section{Funding}

None.

\section{Availability of data and materials}

All data relevant to the given manuscript have been stored in a separate file, which can be made freely available to external investigators upon request.

\section{Declarations}

Ethics approval and consent to participate.

The study protocol was approved by the Xuzhou Center for Disease Control and Prevention and was conducted in accordance with the principles of the Declaration of Helsinki (1975, revised 2000). All participants provided written informed consent.

Consent for publication

Not applicable.

Competing interests

No potential conflicts of interest relevant to this article were reported.

\section{Author details}

${ }^{1}$ Department of Control and Prevention of Chronic Non-communicable Diseases of Xuzhou Center for Disease Control and Prevention, 142 West Erhuan Road, Xuzhou, Jiangsu, China. ${ }^{2}$ Department of Respiratory Medicine, Affiliated Hospital of Xuzhou Medical University, Xuzhou, China.

Received: 7 September 2021 Accepted: 30 November 2021 Published online: 04 January 2022

\section{References}

1. Vogelmeier CF, et al. Global strategy for the diagnosis, management, and prevention of chronic obstructive lung disease 2017 Report. GOLD Executive Summary. Am J Respir Crit Care Med. 2017;195(5):557-82.

2. GBD 2017 DALYs and HALE Collaborators. Global, regional, and national disability-adjusted life-years (DALYs) for 359 diseases and injuries and healthy life expectancy (HALE) for 195 countries and territories, 1990-2017: a systematic analysis for the Global Burden of Disease Study 2017. Lancet 2018;392(10159):1859-922.

3. Fang $L$, et al. Chronic obstructive pulmonary disease in China: a nationwide prevalence study. Lancet Respir Med. 2018;6(6):421-30. 
4. Wang C, et al. China Pulmonary Health Study Group. Prevalence and risk factors of chronic obstructive pulmonary disease in China (the China Pulmonary Health [CPH] study): a national cross-sectional study. Lancet. 2018;391(10131):1706-17.

5. Zhou M, et al. Mortality, morbidity, and risk factors in China and its provinces, 1990-2017: a systematic analysis for the Global Burden of Disease Study 2017. Lancet. 2019;394(10204):1145-58.

6. Flenley DC. Sleep in chronic obstructive lung disease. Clin Chest Med. 1985;6:651-61.

7. Shawon MS, et al. Current evidence on prevalence and clinical outcomes of co-morbid obstructive sleep apnea and chronic obstructive pulmonary disease: a systematic review. Sleep Med Rev. 2017;32:58-68.

8. Donovan $L M$, et al. Poor outcomes among patients with chronic obstructive pulmonary disease with higher risk for undiagnosed obstructive sleep apnea in the LOTT cohort. J Clin Sleep Med. 2019;15(1):71-7.

9. McNicholas WT. Chronic obstructive pulmonary disease and obstructive sleep apnea: overlaps in pathophysiology, systemic inflammation, and cardiovascular disease. Am J Respir Crit Care Med. 2009;180(8):692-700.

10. Du W, et al. Obstructive sleep apnea, COPD, the overlap syndrome, and mortality: results from the 2005-2008 national health and nutrition examination survey. Int J Chron Obstruct Pulmon Dis. 2018;13:665-74.

11. Marin JM, Soriano JB, Carrizo SJ, Boldova A, Celli BR. Outcomes in patients with chronic obstructive pulmonary disease and obstructive sleep apnea: the overlap syndrome. Am J Respir Crit Care Med. 2010;182(3):325-31.

12. Marin JM, Carrizo SJ, Vincente E, Agusti AG. Long-term cardiovascular outcomes in men with obstructive sleep apnoea-hypopnoea with or without treatment with continuous positive airway pressure: an observational study. Lancet. 2005;365(9464):1046-53.

13. White $L H$, Bradley TD. Role of nocturnal rostral fluid shift in the pathogenesis of obstructive and central sleep apnoea. J Physiol. 2013;591(5):1179-93.

14. Krachman SL, et al. Effect of emphysema severity on the apnea-hypopnea index in smokers with obstructive sleep apnea. Ann Am Thorac Soc. 2016;13(7):1129-35.

15. Ustun B, Westover MB, Rudin C, Bianchi MT. Clinical prediction models for sleep apnea: the importance of medical history over symptoms. J Clin Sleep Med. 2016;12(2):161-8.

16. Sun WL, et al. Impact of obstructive sleep apnea on pulmonary hypertension in patients with chronic obstructive pulmonary disease. Chin Med J (Engl). 2019;132(11):1272-82.

17. Wang N, et al. Geographical disparity and associated factors of COPD prevalence in China: a spatial analysis of national cross-sectional study. Int J Chron Obstruct Pulmon Dis. 2020;15:367-77.

18. von Elm E et al. The Strengthening the Reporting of Observational Studies in Epidemiology (STROBE) statement: guidelines for reporting observational studies. Lancet. 2007;370(9596):1453-7.

19. Berry RB et al. Rules for scoring respiratory events in sleep: update of the 2007 AASM Manual for the Scoring of Sleep and Associated Events. Deliberations of the Sleep Apnea Definitions Task Force of the American Academy of Sleep Medicine. J Clin Sleep Med. 2012;8(5):597-619.

20. Sleep and respiratory disorders group, society of respiratory diseases, Chinese Medical Association. Guidelines for diagnosis and treatment of obstructive sleep apnea and hypopnea syndrome (2011 Revision). Chin J Tuberculosis Resp Dis. 2012;35(1):9-12.

21. Mahler DA, Wells CK. Evaluation of clinical methods for rating dyspnea. Chest. 1988:93(3):580-6.

22. Jones PW, et al. Development and first validation of the COPD Assessment Test. Eur Respir J. 2009;34(3):648-54.

23. Chung F, et al. High STOP-Bang score indicates a high probability of obstructive sleep apnoea. Br J Anaesth. 2012;108(5):768-75.

24. Zigmond AS, Snaith RP. The hospital anxiety and depression scale. Acta Psychiatr Scand. 1983;67(6):361-70.

25. Charlson ME, Pompei P, Ales KL, MacKenzie CR. A new method of classifying prognostic comorbidity in longitudinal studies: development and validation. J Chronic Dis. 1987:40(5):373-83.

26. Steveling EH, et al. Predictors of the overlap syndrome and its association with comorbidities in patients with chronic obstructive pulmonary disease. Respiration. 2014;88(6):451-7.

27. Hu W, et al. Obstructive sleep apnea increases the prevalence of hypertension in patients with chronic obstructive disease. COPD. 2020;17(5):523-32.
28. Xiong $\mathrm{MQ}$, et al. Analysis of risk factors and consequences for concurrent obstructive sleep apnea in chronic obstructive pulmonary disease patients. Zhonghua Jie He He Hu Xi Za Zhi. 2019;42(11):832-7.

29. Sole RX et al. Age, gender, neck circumference, and Epworth sleepiness scale do not predict obstructive sleep apnea (OSA) in moderate to severe chronic obstructive pulmonary disease (COPD): The challenge to predict OSA in advanced COPD PLoS One. 2017;12(5):e0177289.

30. Poulain $\mathrm{M}$ et al. The effect of obesity on chronic respiratory diseases: pathophysiology and therapeutic strategies. CMAJ. 2006;174(9):1293-9.

31. Deegan PC, McNicholas WT. Pathophysiology of obstructive sleep apnoea. Eur Respir J. 1995;8(7):1161-78.

32. Edwards BA, Eckert DJ, Jordan AS. Obstructive sleep apnoea pathogenesis from mild to severe: Is it all the same? Respirology 2017;22(1):33-42.

33. Peppard PE, Young T, Palta M, Dempsey J, Skatrud J. Longitudinal study of moderate weight change and sleep-disordered breathing. JAMA. 2000;284(23):3015-21.

34. Hang LW, et al. Predictive factors warrant screening for obstructive sleep apnea in COPD: a Taiwan National Survey. Int J Chron Obstruct Pulmon Dis. 2016;11:665-73.

35. Langsetmo L, Platt RW, Ernst P, Bourbeau J. Underreporting exacerbation of chronic obstructive pulmonary disease in a longitudinal cohort. Am J Respir Crit Care Med. 2008;177(4):396-401.

36. Xie J, Li F. Association of sleep overlap syndrome with type 2 diabetes in a cross-sectional study. Beijing Da Xue Xue Bao Yi Xue Ban. 2019;51 (2):252-5.

37. Papachatzakis I, Velentza L, Zarogoulidis P, Kallianos A, Trakada G. Comorbidities in coexisting chronic obstructive pulmonary disease and obstructive sleep apnea-overlap syndrome. Eur Rev Med Pharmacol Sci. 2018;22(13):4325-31.

38. Fabbri LM, Lupp IF, Beghé B, Rabe KF. Complex chronic comorbidities of COPD. Eur Respir J. 2008;31(1):204-12.

39. Xiong $\mathrm{M}$, et al. The screening value Of ESS, SACS, BQ, and $\mathrm{SBQ}$ on obstructive sleep apnea in patients with chronic obstructive pulmonary disease. Int J Chron Obstruct Pulmon Dis. 2019;14:2497-505.

40. Li Z, et al. Characterization of primary symptoms leading to Chinese patients presenting at hospital with suspected obstructive sleep apnea. J Thorac Dis. 2014;6(5):444-51.

41. Agusti AG. Systemic effects of chronic obstructive pulmonary disease. Proc Am Thorac Soc. 2005;2:367-70.

42. He BT, et al. Coexistence of OSA may compensate for sleep related reduction in neural respiratory drive in patients with COPD. Thorax. 2017;72(3):256-62.

43. McMahon MJ, Sheikh KL, Andrada TF, Holley AB. Using the STOPBANG questionnaire and other pre-test probability tools to predict OSA in younger, thinner patients referred to a sleep medicine clinic. Sleep Breath. 2017;21(4):869-76.

44. Heinzer $R$, et al. Prevalence of sleep-disordered breathing in the general population: the HypnoLaus study. Lancet Respir Med. 2015;3(4):310-8.

45. Kashyap R, Hock LM, Bowman TJ. Higher prevalence of smoking in patients diagnosed as having obstructive sleep apnea. Sleep Breath. 2001;5(4):167-72.

46. Shaikh M, Sood RG, Sarkar M, Thakur V. Quantitative computed tomography $(\mathrm{CT})$ assessment of emphysema in patients with severe chronic obstructive pulmonary disease (COPD) and its correlation with age, sex, pulmonary function tests, BMI, smoking, and biomass exposure. Pol J Radiol. 2017:82:760-6.

47. Sharma B, et al. Obstructive airways disease and obstructive sleep apnea: effect of pulmonary function. Lung. 2011;189(1):37-41.

48. McNicholas WT. Comorbid obstructive sleep apnoea and chronic obstructive pulmonary disease and the risk of cardiovascular disease. J Thorac Dis. 2018;10(Suppl 34):S4253-61.

49. Biselli $\mathrm{P}$, et al. The effect of increased lung volume in chronic obstructive pulmonary disease on upper airway obstruction during sleep. J Appl Physiol. 1985;1 19(3):266-71.

50. Mulloy E, McNicholas WT. The ophylline in obstructive sleep apnea. A double-blind evaluation. Chest. 1992;101(3):753-7.

\section{Publisher's Note}

Springer Nature remains neutral with regard to jurisdictional claims in published maps and institutional affiliations. 